\title{
The Adsorption Mechanism of Water-based Ink Particles onto Cellulosic Fibers
}

\author{
Yun Cheng, ${ }^{a}$ Hongjie Zhang, ${ }^{\mathrm{a}, \mathrm{b}, *}$ Xue Zhang, ${ }^{\mathrm{a}}$ Wenhui Zhang, ${ }^{\mathrm{b}, *}$ Chuanfei Shi, ${ }^{\mathrm{b}}$ \\ Rongyao Zhu, ${ }^{\mathrm{b}}$ Ting Jiao, ${ }^{\mathrm{b}}$ and Haiyan Zhang ${ }^{\mathrm{b}}$
}

\begin{abstract}
Water-based flexographic-printed ink has attracted much attention due to the reduced emission of volatile organic compounds in the printing process. However, it is difficult to remove water-based ink particles with small particle size and high hydrophilicity because they are easily reabsorbed onto cellulosic fibers during wastepaper recycling. In this paper, the absorption mechanism of water-based ink particles onto fibers was studied by using isotherm models and adsorption dynamic kinetics models at different temperatures. The adsorption process was fitted to the Freundlich isotherm, and the adsorption behavior was spontaneous and exothermic processes with an increase of entropy. It fitted well with the pseudo-second-order rate model, and the equilibrium adsorption amounts at three temperature conditions were $2.55,2.34$, and $2.21 \mathrm{mg} / \mathrm{g}$, respectively. The $B$ value was $9.20 \mathrm{~g} \cdot \mathrm{mg}^{-1} \cdot \mathrm{min}^{-1}$, and the $E_{\mathrm{a}}$ value was $15.6 \mathrm{~kJ} \cdot \mathrm{mol}^{-1}$. The results showed that it was easier to remove the waterbased ink particles from cellulosic fibers under shorter contact time and higher operation temperature during wastepaper recycling. It would be helpful to optimize the wastepaper recycling operation and to develop a novel deinking process.
\end{abstract}

Keywords: Water-based ink; Cellulosic fibers; Adsorption kinetics; Adsorption isotherms

Contact information: a: China National Pulp and Paper Research Institute Co. Ltd., Beijing 100102, China; b: Tianjin Key Lab of Pulp \& Paper, Tianjin University of Science \& Technology, Tianjin 300457, China; *Corresponding authors: hongjiezhang@ cnppri.com; zhangwhui@tust.edu.cn

\section{INTRODUCTION}

Wastepaper recycling reduces the consumption of natural plant resources in the paper industry, and it is beneficial to alleviate environmental pressures. Recycled fibers make up one third of the paper-based fibers globally (Xiang et al. 2019). The huge challenge for extensive use of recycled fibers is to develop high-efficiency ink removal processes. Generally, the efficiency of ink removal is determined by the species of fibers, inks, and printing processes (Tsatsis et al. 2017). Compared with oil-based ink, waterbased ink is welcomed in the printing and packaging industries. However, as little as 5\% flexographic newsprints paper in a recycling furnish can significantly reduce the brightness of secondary fibers (Larson 1997). In addition, it is difficult for water-based ink printed paper or paperboard to be deinked by the traditional flotation process due to the small particle size and high hydrophilicity of water-based ink particles. The presence of waterbased ink particles seriously affects the optical property of the recycled fibers.

Water-based ink is characterized by using water as the medium or major liquid component in which most of additives are dissolved or suspended. In general, water-based ink contains the carboxylated polymer and free alkali, such as ammonia hydroxide, which is used to dissolve the resin (Fillat et al. 2015). In the water-based ink printing process, the 
$\mathrm{pH}$ is gradually reduced due to the base vaporization, which results in the desolubilization of polymers to improve the attachment of pigments to the substrate. Under high $\mathrm{pH}$ conditions in wastepaper recycling, the carboxylated polymer is soluble and the binders of water-based ink are dissolved continually; concurrently, the size of ink particles decreases significantly (Lee et al. 2013). Due to the small particle size $(0.1$ to $1 \mu \mathrm{m})$ and hydrophilic properties of water-based ink particles (Kemppainen et al. 2011), it is difficult to remove them from fibers, and they tend to reabsorb on the fiber surface or to deposit inside the lumen of fibers in the traditional flotation deinking process. The re-deposited ink is quite difficult to remove in the subsequent washing stages without substantial loss of fibers. Some additives in the water-based ink (such as surfactants and inorganic ions) and recycling conditions can decrease the reabsorption amount of water-based ink particles onto fibers (Gecol et al. 2004). The published research mainly focuses on the optimization of reabsorption process and related pulping parameters, but there has been a lack of published work on the adsorption mechanism of ink particles onto fibers.

In this work, the adsorption mechanism of water-based ink particles onto fibers was studied from the viewpoint of the adsorption isotherms, kinetics, and thermodynamics. Specially, the adsorption isotherm model of water-based ink particles onto cellulosic fibers was investigated by varying the contact time and temperature in the adsorption process to determine the adsorption capacity; the thermodynamic model was used to explore the adsorption possibility and the adsorption degree of water-based ink particles onto fibers; the kinetics model was applied to clarify the effect of contact time on the deposition of water-based ink particles onto fibers. The main objective of this study was to schematically investigate the adsorption mechanism of water-based ink particles onto fibers and to guide the water-based ink removal process in industrial processes.

\section{EXPERIMENTAL}

\section{Materials}

Water-based ink (Shanggu Caitong-TGS; black) was obtained from Tianjin Hanlin Tongshang Technology Co., Ltd. (Tianjin, China). The physicochemical properties of secondary fiber are hard to control due to different fiber types, additives, and seasonal variations in the fiber recovery system. Therefore, softwood bleached kraft pulp (SBKP) was chosen as the raw material in the adsorption simulation process in order to control the key parameters of the adsorption procedure and to simplify the fiber adsorption process.

\section{Water-based Ink Aging}

The water-based ink was aged before the adsorption experiment to simulate the maturation of water-based ink during the printing process. The water-based ink suspension, which included $18 \mathrm{wt} \%$ carbon black, $10 \mathrm{wt} \%$ polyacrylate, $5 \mathrm{wt} \%$ additives, and $67 \mathrm{wt} \%$ water, was aged at $105{ }^{\circ} \mathrm{C}$ for $8 \mathrm{~h}$. As the size of most water-based ink particles in the flotation deinking process was less than $1 \mu \mathrm{m}$, the size distribution of the water-based ink particles was investigated by a Nano Brook Laser Particle Size Analyzer (Model 90 PLUS/BI, Brookhaven Instruments Co. Ltd., New York, USA). The grinded ink particles were dispersed in water and homogenized with a high-speed disperser to obtain a uniformly dispersed ink suspension. 


\section{Adsorption Procedure}

The apparatus for the simulative adsorption experiment of ink particles onto fibers is illustrated in Fig.1. The apparatus consisted of a $500 \mathrm{~mL}$ beaker to hold the suspension of ink particles and testing fibers, a 200-mesh screening chamber to filter out fibers that interfere the concentration measurement of water-based ink particles, agitator, and magnetic stirring bar (the rotation speed was set at $600 \mathrm{rpm}$ ) to maintain the stable suspension state of the mixture. The suspension of ink particles and fibers was kept at 10, 20 , or $30{ }^{\circ} \mathrm{C}$. The concentration of the ink particles in the suspension before and after the adsorption process was determined by transferring $2.5 \mathrm{~mL}$ of filtrate in the screening chamber to the photometric detector for UV/Vis measurement. Based on the ink particle concentration in the suspension before and after the adsorption process, the adsorption capacity $\left(q_{\mathrm{e}}\right)$ of ink particles onto fibers was determined using Eq. 1,

$$
q_{e}=\frac{C_{0}-C_{e}}{m} \times V
$$

where $C_{0}$ and $C e\left(\mathrm{~g} \cdot \mathrm{L}^{-1}\right)$ are the initial and equilibrium concentrations of water-based ink particles, $V(\mathrm{~L})$ is the volume of the mixing suspension, and $m(\mathrm{~g})$ is the mass of fibers in the mixing suspension.

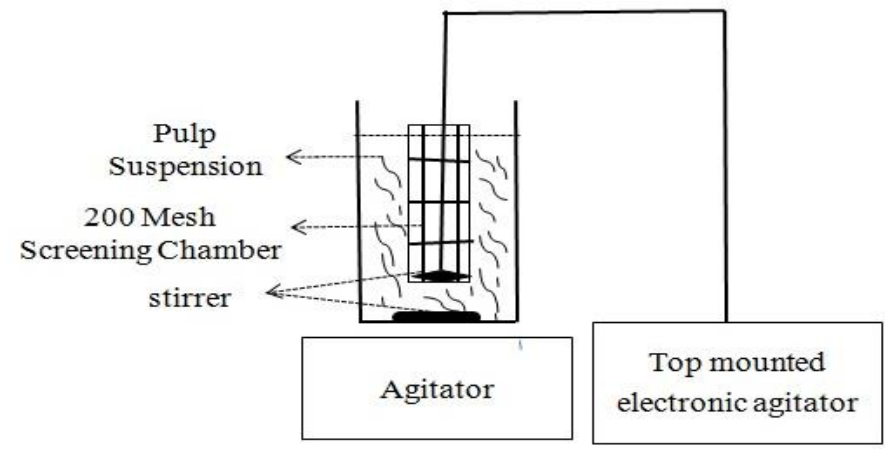

Fig. 1. The experimental apparatus for the adsorption of water-based ink particles onto fibers

\section{Determination of Water-based Ink Particles Concentration}

The maximal absorbing wavelength $\left(\lambda_{\max }\right)$ for the water-based ink particles was determined at $700 \mathrm{~nm}$ with a UV/Vis spectrometer (Model T6, Beijing General Analysis Instrument Co. Ltd., Beijing, China). A linear trend between the concentration of waterbased ink particles in the suspension and the absorbance of water-based ink particles suggested that Beer-Lambert Law was applicable to water-based ink particles in the testing concentration range.

\section{RESULTS AND DISCUSSION}

\section{Characterization of Water-based Ink Particles and Cellulosic Fibers}

As shown in Fig. 2, the size distribution of the water-based ink particles ranged from 92 to $236 \mathrm{~nm}$. Based on the previous research, the morphological properties of cellulosic fibers have significant impact on the adsorption and accumulation process of water-based ink particles onto cellulosic fibers, especially the pore morphology, such as pore shape, pore volume, and pore size distribution (Mahfoudhi and Boufi 2017). The pore size of SBKP fibers was divided into wide ranges, and the majority had relatively bigger pore volume (bigger than $100 \mathrm{~nm}$ ). 


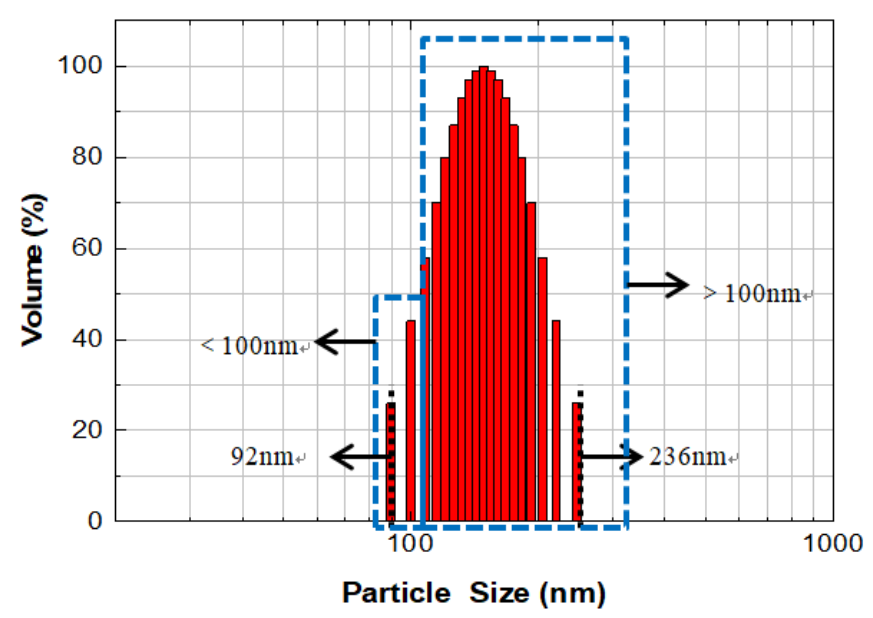

Fig. 2. The size distribution of the water-based ink particles after grinding treatment

\section{Effect of Contact Time and Temperature on the Adsorption Process}

In the adsorption process of water-based ink particles onto fibers, contact time and temperature can affect the adsorption behavior (including equilibrium time, adsorption rate, and equilibrium adsorption capacity) of the solid-solid interface (Fan et al. 2017). The effect of contact time $(t)$ and temperature on the adsorption capacity $\left(q_{\mathrm{e}}\right)$ of water-based ink particles onto fibers are shown in Fig. 3.

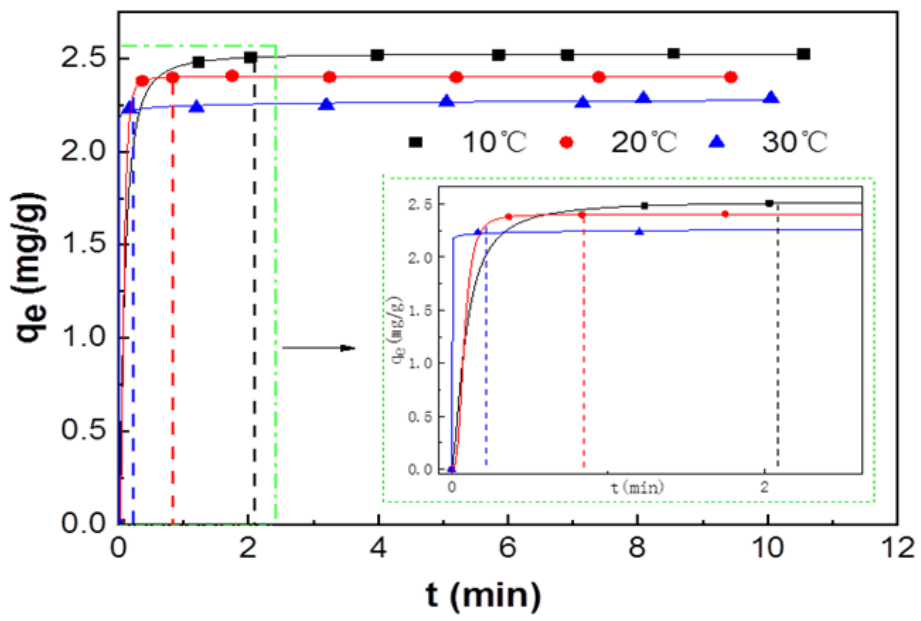

Fig. 3. Effect of contact time $(t)$ and temperature on the adsorption capacity $\left(q_{\mathrm{e}}\right)$ of water-based ink particles onto fibers (Initial water-based ink concentration of $0.36 \mathrm{~g} / \mathrm{L}$; the fiber content of $1 \%$ )

Figure 3 shows that at any temperature, the adsorption capacity of water-based ink particles onto fibers was dramatically increased at the very beginning of adsorption procedure and then reached the adsorption equilibrium with the increase of contact time. According to the adsorption curve in Fig. 3, the adsorption process could be divided into two phases: a rapid-adsorption phase and a slow-adsorption phase. The former indicated that the adsorption capacity of ink particles onto fibers dramatically increased with the contact time, and the latter showed that the adsorption capacity tended to stabilize. The rapid phase was due to easily available active adsorption sites on the fiber surface (Devi and Saroha 2016). As porous materials, fibers have many folds and pores on their surface that allow the adsorption/accumulation of ink particles, as shown in Figs. 4(a) and (c). 
Moreover, there was a certain proportion of ink particles with small size (less than 100 $\mathrm{nm}$ ), which could easily deposit onto the pores of fiber surface, as shown in Figs. 4(b) and (d) (Bhunia et al. 2013). The slow-adsorption phase represented the diffusion process, controlled by the ink particles concentration gradient between the fiber surface and the bulk suspension (Liu et al. 2014). Finally, the adsorption capacity did not change after the adsorption equilibrium was reached. Therefore, in an industrial deinking process, it is important to remove the ink within a short time to prevent the water-based ink particles from redepositing onto fibers.

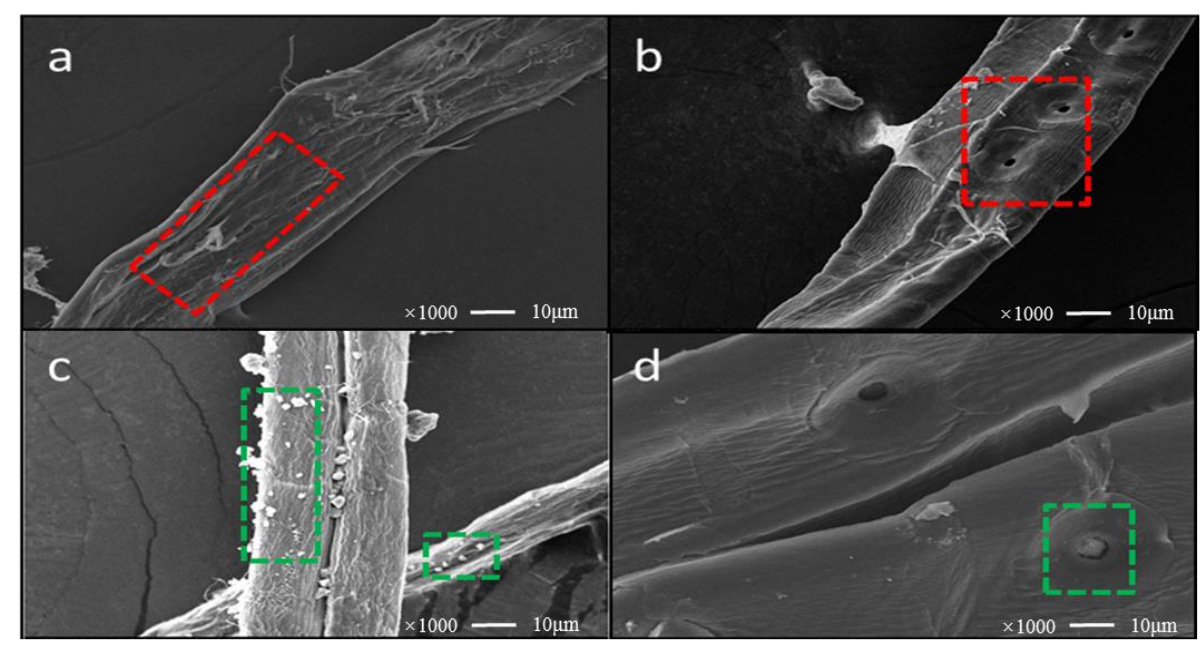

Fig. 4. SEM images for the water-based ink particles onto fibers

Figure 3 also shows that the adsorption rate increased with the increase of temperature, which was attributed to the increased diffusion rate of the water-based ink particles onto fibers. Under the temperature of 10,20 , and $30^{\circ} \mathrm{C}$, the adsorption amounts of water-based ink particles onto the fibers at equilibrium $\left(q_{\mathrm{e}}\right)$ were $2.55,2.33$, and 2.18 $\mathrm{mg} / \mathrm{g}$, respectively, indicating that the adsorption amounts of ink particles in fibers at equilibrium $\left(q_{\mathrm{e}}\right)$ decreased with the increase of temperature.

\section{Adsorption Isotherms and Thermodynamic Analysis}

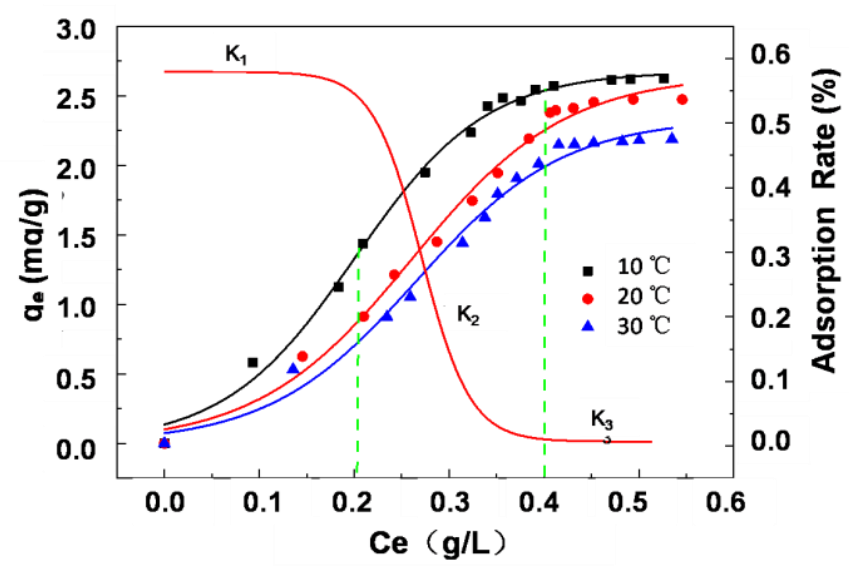

Fig. 5. The adsorption isotherms of water-based ink particles onto fiber surfaces (Initial waterbased ink concentration of 0 to $0.6 \mathrm{mg} / \mathrm{L}$; fibers content of $1 \%$; contact time of $30 \mathrm{~min}$ ) 
Figure 5 shows the adsorption isotherms of water-based ink particles onto fibers under three temperatures $\left(10,20\right.$, and $\left.30{ }^{\circ} \mathrm{C}\right)$. Based on the relationship between the absorption amount $\left(q_{\mathrm{e}}\right)$ of ink particles onto fiber surface and the residual amount of ink particles in aqueous phase $\left(C_{\mathrm{e}}\right)$, the development trend of adsorption rate $(K)$ was studied with the increase of ink particle concentration. As shown in Fig. 5, the adsorption rate $(K)$ decreased with increasing ink particle concentration $\left(C_{\mathrm{i}}\right)$. When $C_{\mathrm{i}}$ was smaller than $0.2 \mathrm{~g} / \mathrm{L}, K$ was relatively bigger due to the larger concentration gradient of ink particles between the aqueous phase and fiber surface. With the increase of $C_{\mathrm{i}}, K$ gradually decreased due to the reduction of adsorption sites on the fiber surface. When $C_{\mathrm{i}}$ was higher than $0.4 \mathrm{~g} / \mathrm{L}$, the adsorption sites on fiber surface were almost filled, so $K$ was close to 0 . It was evident that the fiber adsorption capacity increased with the increased concentration of ink particles in solution (Gobi et al. 2011). With the increase of initial concentration of ink particles, the adsorption sites on fiber surface were almost saturated, leading to less binding sites of ink particles on the fiber surfaces.
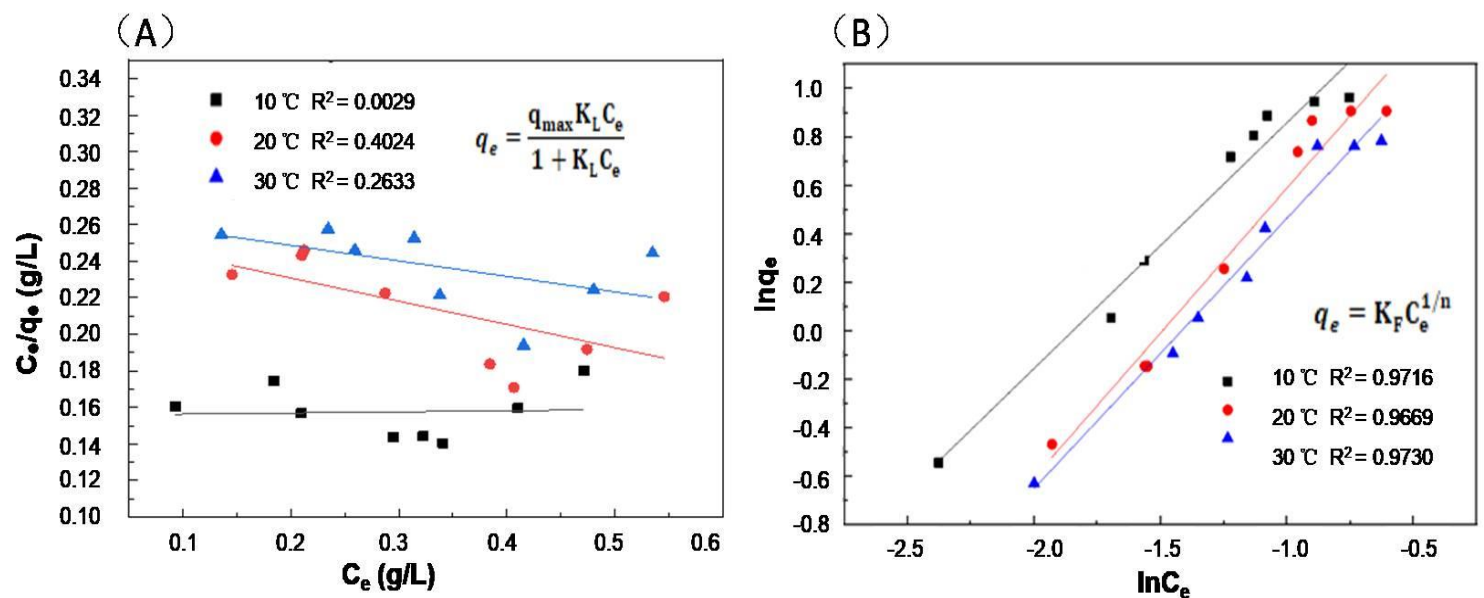

Fig. 6. Fitting results of the adsorption data for ink particles onto cellulosic fibers at varying experimental temperatures: $(A)$ the adsorption experiment data were fitted with the Langmuir model, where the inset equation was the non-liner theoretical equation of the Langmuir isotherm model; (B) the adsorption experiment data were fitted with Freundlich isotherm model, where the inset equation was the non-liner theoretical equation of the Freundlich isotherm model.

The adsorption data for ink particles onto fibers was correlated with the Langmuir and Freundlich isotherm models. The fitting results are shown in Fig. 6. The numerical value of the determination coefficient $\mathrm{R}^{2}$ was higher than 0.9 when the adsorption experiment data were fitted to the Freundlich isotherm model (Fig. 6(A)); meanwhile, the $\mathrm{R}^{2}$ was much smaller than 0.5 when the adsorption experiment data were fitted to the Langmuir isotherm model (Fig. 6(B)). The fitting results indicated that the adsorption model of water-based ink particles onto fibers was fitted better to the Freundlich isotherm than to the Langmuir isotherm. According to the fitting curve, the $1 / n$ and $\ln K_{\mathrm{F}}$ of the Freundlich isotherm model were determined, which were calculated from the slope and intercept of the fitting curve, respectively. The $K_{F}$ defines the adsorption capacities of the water-based ink particles onto fibers. The larger $K_{F}$ indicates greater adsorption per unit mass of adsorbent. The $K_{F}$ values at 10,20 , and $30{ }^{\circ} \mathrm{C}$ in Table 1 were 6.50, 5.95, and 4.85, respectively, indicating that the adsorption amounts of water-based ink particles onto fibers decreased with increased temperature. The value of $1 / n$ is the empirical parameter for Freundlich equation. Generally, the adsorption process can be performed easily when $1 / n$ is 0.1 to 1.0 ; it is difficult for it to occur when $1 / n$ is more than 2 . As shown in Table 1 , the 
$1 / n$ value of the studied adsorption process was approximately 1 , suggesting that it was easy for the water-based ink particles to deposit onto fiber surfaces. The isotherm constants of Freundlich isotherm model obtained from the fitting results are summarized in Table 1.

As the adsorption data were fitted better to the Freundlich isotherm model, the thermodynamic parameters for the adsorption process were obtained by plotting $\ln K_{F}$ against $1 / T$ according to the Van't Hoff equation (Eq. 2),

$$
\ln K_{\mathrm{F}}=-\frac{\Delta H}{R T}+\frac{\Delta S}{R}
$$

where $R$ is the universal gas constant $\left(8.314 \mathrm{~J} \cdot \mathrm{mol}^{-1} \cdot \mathrm{K}^{-1}\right), T$ is the absolute temperature $(\mathrm{K})$, and $\Delta H$ and $\Delta S$ are enthalpy $\left(\mathrm{kJ} \cdot \mathrm{mol}^{-1}\right)$ and entropy changes $\left(\mathrm{J} \cdot \mathrm{mol}^{-1} \cdot \mathrm{K}^{-1}\right)$ of the adsorption process, respectively, which can be calculated from the slope and intercept of the fitting curve. The free energy $(\Delta G)$ of the adsorption process was obtained from the difference $(\Delta H-T \Delta S)$. As shown in Table 1 , the negative $\Delta H\left(-10.39 \mathrm{~kJ} \cdot \mathrm{mol}^{-1}\right)$ value indicated the exothermic nature of the adsorption process. The $\Delta S\left(12.67 \mathrm{~J} \cdot \mathrm{mol}^{-1} \cdot \mathrm{K}^{-1}>0\right)$ value showed that the adsorption entropy increased in the process, suggesting that there were strong affinity between fibers and water-based ink particles. The adsorption process was spontaneous because all the $\Delta G$ values were less than zero. Therefore, the low adsorption temperature is benefit to the adsorption process.

Table 1. Isotherm Constants of Freundlich and Thermodynamic Parameters for the Adsorption of Water-based Ink Particles onto Fibers at Different

Temperatures

\begin{tabular}{|c|c|c|c|c|c|c|}
\hline$T\left({ }^{\circ} \mathrm{C}\right)$ & $K_{\mathrm{F}}$ & $1 / n$ & $\mathrm{R}^{2}$ & $\Delta H\left(\mathrm{~kJ} \cdot \mathrm{mol}^{-1}\right)$ & $\Delta S\left(\mathrm{~J} \cdot \mathrm{mol}^{-1} \cdot \mathrm{K}^{-1}\right)$ & $\Delta G\left(\mathrm{~kJ} \cdot \mathrm{mol}^{-1}\right)$ \\
\hline 10 & 6.50 & 1.01 & 0.9716 & -10.39 & 12.67 & -13.97 \\
\hline 20 & 5.95 & 1.19 & 0.9669 & -10.39 & 12.67 & -14.10 \\
\hline 30 & 4.85 & 1.11 & 0.9730 & -10.39 & 12.67 & -14.22 \\
\hline
\end{tabular}

\section{Adsorption Kinetics}

(A)

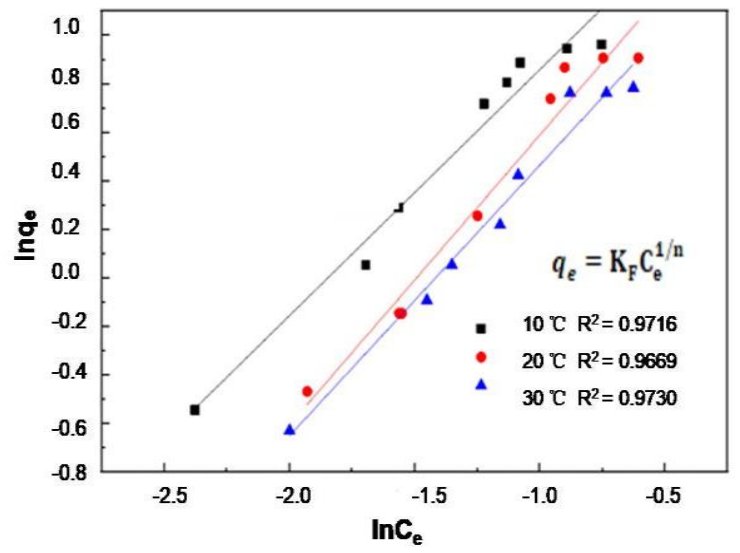

(B)

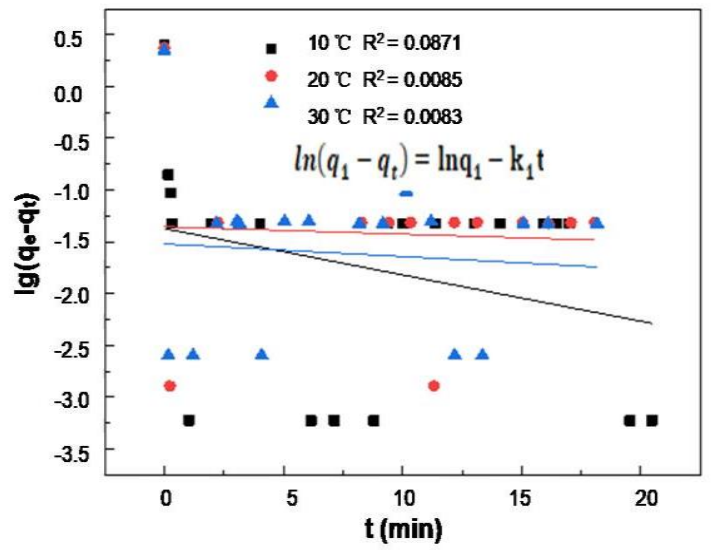

Fig. 7. Adsorption kinetic process of water-based ink particles onto fibers: $(A)$ the fitting results of the experimental data based on the Lagergren's first-order rate model, the insert equation was the Lagergren's first-order rate equation; $(B)$ the fitting results of the experiment data based on the pseudo-second-order rate model, the insert equation was the Ho's second-order rate equation. 
The pseudo-first-order and pseudo-second-order rate equations were employed to interpret the experimental data. As shown in Fig. 7, the coefficient $\mathrm{R}^{2}$ of the fitting equation based on Lagergren's first-order rate model was much smaller than 0.1 (Fig. 7(A)); meanwhile, the coefficient $\mathrm{R}^{2}$ of the fitting equation based on the Ho's second-order rate model was 0.999 and very close to 1 (Fig. 7(B)). Based on the coefficients, the Ho's second-order rate equation was more suitable to describe the adsorbing kinetic process of water-based ink particles onto fiber, and the related kinetic parameters at 10,20 , and $30{ }^{\circ} \mathrm{C}$ are given in Table 2. The value of $k_{2}$ increased with the increase of temperature, suggesting that the diffusion rate of water-based ink particles was greater in high temperature; $q_{e}$ decreased with the increase of temperature because the desorption rate was faster than the adsorption rate at a higher temperature.

Table 2. Kinetic Parameters for the Adsorption Process of Water-Based Ink Particles onto Fibers at 10,20 , and $30^{\circ} \mathrm{C}$

\begin{tabular}{|c|c|c|c|}
\hline$T\left({ }^{\circ} \mathrm{C}\right)$ & $k_{2}\left(\mathrm{~g} \cdot \mathrm{mg}^{-1} \cdot \mathrm{min}^{-1}\right)$ & $q_{\mathrm{e}}\left(\mathrm{mg} \cdot \mathrm{g}^{-1}\right)$ & $\mathrm{R}^{2}$ \\
\hline 10 & 13.37 & 2.55 & 0.999 \\
\hline 20 & 17.23 & 2.34 & 0.999 \\
\hline 30 & 20.68 & 2.21 & 0.999 \\
\hline
\end{tabular}

The values of $k_{2}$ at different temperatures were treated with the Arrhenius equation as Eq. 3,

$$
\ln k_{2}=B-\frac{E_{a}}{R T}
$$

where $B$ is the frequency of adsorption $\left(\mathrm{g} \cdot \mathrm{mg}^{-1} \cdot \mathrm{min}^{-1}\right), E_{a}$ is the activation energy of reaction $\left(\mathrm{kJ} \cdot \mathrm{mol}^{-1}\right), R$ is the universal gas constant $\left(8.314 \mathrm{~J} \cdot \mathrm{mol}^{-1} \cdot \mathrm{K}^{-1}\right)$, and $T$ is the absolute temperature.

The values of $\ln k_{2}$ was plotted against the reciprocal of absolute temperature $(1 / T)$ to determine the corresponding $B$ and $E_{a}$ from the intercept and the slope of regression line, respectively. The $B$ was $9.20 \mathrm{~g} \cdot \mathrm{mg}^{-1} \cdot \mathrm{min}^{-1}$ and the $E_{a}$ was $15.60 \mathrm{~kJ} \cdot \mathrm{mol}^{-1}$. Generally, sorption processes governed by an activation energy have energies greater than 25 to 30 $\mathrm{kJ} \cdot \mathrm{mol}^{-1}$; sorption processes governed by diffusion have energies less than 25 to 30 $\mathrm{kJ} \cdot \mathrm{mol}^{-1}$ (Ho et al. 2000). The $E_{a}$ value of the adsorption process was less than $30 \mathrm{~kJ} \cdot \mathrm{mol}^{-1}$, indicating that diffusion behavior also happened in the adsorption process.

\section{CONCLUSIONS}

1. The adsorption capacity of water-based ink particles onto cellulosic fibers decreased with increasing temperature, and the adsorption amount increased with increased contact time. Adsorption isotherms indicated that the adsorption behavior of waterbased ink particles onto cellulosic fibers was more fitted with the Freundlich isotherm model than the Langmuir isotherm model. In addition, a thermodynamic study revealed that the absorption process between water-based ink particles and cellulosic fibers was a spontaneous and exothermic process.

2. The kinetic study suggested that the adsorption process of water-based ink particles onto cellulosic fibers fitted very well with the pseudo-second-order kinetic model over a temperature range. The activation energy $\left(E_{a}\right)$ of the sorption process was 15.6 $\mathrm{kJ} \cdot \mathrm{mol}^{-1}$, and the diffusion behavior also happened in the adsorption process. 


\section{ACKNOWLEDGMENTS}

The authors acknowledge the financial support from the National Natural Science Foundation of China (Grant No. 31670588).

\section{REFERENCES CITED}

Bhunia, A., Vasylyeva, V., and Janiak, C. (2013). "From a supramolecular tetranitrile to a porous covalent triazine-based framework with high gas uptake capacities," Chem. Commun. 49(38), 3961. DOI: 10.1039/C3CC41382A

Devi, P., and Saroha, A. K. (2016). "Utilization of sludge based adsorbents for the removal of various pollutants: A review," Sci. Total Environ. S0048969716324196. DOI: $10.1016 / j . s c i t o t e n v .2016 .10 .220$

Fan, J., Li, T., Ren, Y., Qian, X., Wang, Q., Shen, J., Ni. Y. H. (2017). "Interaction between two oppositely charged starches in an aqueous medium containing suspended mineral particles as a basis for the generation of cellulose-compatible composites," Ind. Crops Prod. 97, 417-424. DOI: 10.1016/j.indcrop.2016.12.048

Fillat, U., De Eugenio, L. I., and Martínez, M. J. (2015). "Assessing enzymatic deinking for secondary fibers paper recycling in the presence of flexographic inks," Chem. Eng. J260, 486-491. DOI: 10.1016/j.cej.2014.09.020

Gecol, H., Scamehorn, J. F., Christian, S. D., Grady, B. P., and Riddell, F. E. (2004). "Use of surfactants to remove water-based inks from plastic film: Effect of calcium ion concentration and length of surfactant hydrophobe," Colloid Polym. Sci. 283(2), 154-163. DOI: 10.1007/s00396-004-1082-7

Gobi, K., M. D. Mashitah, and Vadivelu, V. M. (2011). “Adsorptive removal of methylene blue using novel adsorbent from palm oil mill effluent waste activated sludge: Equilibrium, thermodynamics and kinetic studies," Chem. Eng. J 171(3), 1246-1252. DOI: 10.1016/j.cej.2011.05.036

Ho, Y. S., Ng, J. C. Y., and Mckay, G. (2000). "Kinetics of pollutant sorption by biosorbents: Review," Separ. Purif. Method 29(2), 189-232. DOI: 10.1081/SPM100100009

Kemppainen, K., Körkkö, M., and Niinimäki, J. (2011). "Fractional pulping of toner and pigment-based inkjet ink printed papers-ink and dirt behavior," BioResources 6(3), 2977-2989. DOI: 10.1515/HF.2011.079

Larson, E. H. (1997). "Process for removing waterborne flexographic inks from substrates," U.S. Patent No. 5632857.

Lee, C. K., Ibrahim, D., and Che Omar, I. (2013). "Enzymatic deinking of various types of waste paper: Efficiency and characteristics," Process Biochem. 48(2), 299-305. DOI: 10.1016/j.procbio.2012.12.015

Liu, J., Liu, G., and Liu, W. (2014). "Preparation of water-soluble $\beta$-cyclodextrin/ poly(acrylic acid)/graphene oxide nanocomposites as new adsorbents to remove cationic dyes from aqueous solutions," Chem. Eng. J 257, 299-308. DOI:

10.1016/j.cej.2014.07.021

Mahfoudhi, N., and Boufi, S. (2017). "Nanocellulose as a novel nanostructured adsorbent for environmental remediation: A review," Cellulose 24(3), 1171-1197. DOI:

10.1007/s10570-017-1194-0

Tsatsis, D. E., Papachristos, D. K., Valta, K. A., Vlyssides, A. G., and Economides, D. G. 
(2017). "Enzymatic deinking for recycling of office waste paper," J. Environ. Chem. 5(2), 1744-1753. DOI: 10.1016/j.jece.2017.03.007

Xiang, Z., Zhang, J., Liu, Q., Chen, Y., and Li, J. (2019). "Improved dispersion of bacterial cellulose fibers for the reinforcement of paper made from recycled fibers," J. Nanomater. 9(1), 58. DOI: 10.3390/nano9010058

Article submitted: August 13, 2020; Peer review completed: September 22, 2020;

Revised version received and accepted: October 16, 2020; Published: October 23, 2020.

DOI: 10.15376/biores.15.4.9375-9384 